Refraction cases :

$\begin{array}{lllll}\text { (a) Hypermetropia } & \ldots & \ldots & \ldots & 210\end{array}$

$\begin{array}{llllll}\text { (b) Myopia } & \ldots & \ldots & \ldots & \ldots & 30\end{array}$

(c) Hypermetropic astigmatism $\quad \ldots \quad 230$

$\begin{array}{llll}\text { (d) Myopic astigmatism } & \ldots & \ldots & 15\end{array}$

Operations performed

\begin{tabular}{llllllr} 
Excision $\ldots$ & $\ldots$ & $\ldots$ & $\ldots$ & $\ldots$ & $\ldots$ & 36 \\
Iridectomy and extraction & $\ldots$ & $\ldots$ & $\ldots$ & $\ldots$ & 11 \\
Removal of foreign bodies $\ldots$ & $\ldots$ & $\ldots$ & $\ldots$ & 7 \\
Pterygium $\ldots$ & $\ldots$ & $\ldots$ & $\ldots$ & $\ldots$ & $\ldots$ & 4 \\
Minor operations & $\ldots$ & $\ldots$ & $\ldots$ & $\ldots$ & $\ldots$ & 6 \\
\hline
\end{tabular}

Summing up the work, it is obvious that the business of an oculist in a war zone does not include the fine work he is accustomed to in civil practice. The greater part of his time is taken up with the treatment of ophthalmia and the cases of errors of refraction, but there is imposed upon him a far greater responsibility than appears in these activities. It is his business to discriminate between the cases which are fit and which are unfit for duty, and to see that the cases of hysteria and fraud are kept in the lines, and trivial cases treated at the front. It is his business to return those who do reach the base as rapidly as possible. In order to be useful and effect this result, he has to superadd to the expert knowledge gained in civil practice an entirely new and military objective, which calls into place a series of judgments which take time in acquisition, and are exceedingly valuable when once acquired.

\title{
ANNOTATIONS
}

\section{The Beauty Specialist}

We wish to draw the attention of ophthalmic surgeons-and would ask them to keep a record of cases which come under their observation - to patients who have been operated on by unqualified men trading as beauty specialists, under their own name or more frequently that of a fictitious institute. The following case has been brought to our notice.-A woman, aged 37, desirous of becoming a cinema actress and who, as she described it, had "baggy eyes," 
went to an Institute where, under an injection of some local anaesthetic, large pieces of skin were removed from both the upper and lower eyelids. Collodion dressings were applied, and the patient sent home. She suffered intense pain and swelling of the eyelids and conjunctiva, and, according to her own account, one of them became septic. We have also heard of a case in which the palpebral aperture had been enlarged by an external canthotomy performed for "small eyes." Apparently there is nothing in the British law which prevents such operations being performed by unqualified practitioners, unless a fatality occurs. This was instanced some years ago when some unqualified Indian oculists were brought before the courts for removing portions of the eyelids and conjunctiva, and were acquitted.

It would be of service if ophthalmic surgeons would collect similar cases so that some representation could be made with regard to this unqualified practice which seems to be on the increase.

\section{Transactions of the Ophthalmological Society}

Special interest attaches to the Transactions of the Ophthalmological Society of the United Kingdom, Vol. XXXVI, recently issued to members, for not only does it contain an account of the 1918 Congress of the Society but also of the meetings of two of the four affiliated societies, namely, the Oxford Ophthalmological Congress and the Midland Ophthalmological Society. Among the contributions of the affiliated societies the Doyne Memorial Lecture on "Ophthalmology and the War," by Sir William Collins, should be mentioned. It recalls vividly the memory of one whose name is dear to many of us, the late Robert Walter Doyne, founder of the Oxford Congress, and of much besides. For instance, to him is owing the foundation of the Oxford Eye Hospital and the inception of a diploma of ophthalmology in the University of Oxford. These were but the preliminary steps towards a more ambitious dream which he never lived to see fulfilled, which was the rendering of Oxford a centre of ophthalmology for the British Isles. Sir William Collins in speaking of him quotes the fine saying of Ralph Waldo Emerson, "An institution is the lengthened shadow of one man," and never was that truer than in the case of our colleague. The affiliation movement, carried out largely by the then President of the Ophthalmological Society, has our warmest approval, more especially at a time such as this when union is truly strength. Under this scheme the autonomy of the individual society is not affected, but an account of its work will appear in the Transactions. This is an advantage to those societies which have not in the past published a separate volume, as well as to those who belong exclusively to the 